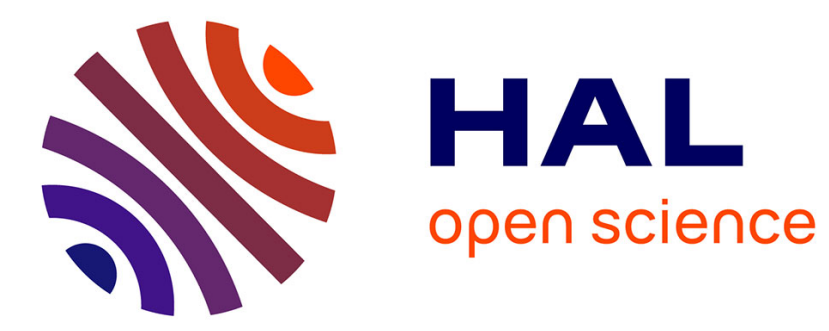

\title{
Time-function reliability of harbour infrastructures from stochastic modelling of corrosion
}

Jérôme Boéro, Franck Schoefs, Humberto Yáñez-Godoy, Bruno Capra

\section{To cite this version:}

Jérôme Boéro, Franck Schoefs, Humberto Yáñez-Godoy, Bruno Capra. Time-function reliability of harbour infrastructures from stochastic modelling of corrosion. European Journal of Environmental and Civil Engineering, 2012, 16 (10), pp.1187-1201. 10.1080/19648189.2012.688611 . hal-01007386

\section{HAL Id: hal-01007386 \\ https://hal.science/hal-01007386}

Submitted on 18 Jan 2017

HAL is a multi-disciplinary open access archive for the deposit and dissemination of scientific research documents, whether they are published or not. The documents may come from teaching and research institutions in France or abroad, or from public or private research centers.
L'archive ouverte pluridisciplinaire HAL, est destinée au dépôt et à la diffusion de documents scientifiques de niveau recherche, publiés ou non, émanant des établissements d'enseignement et de recherche français ou étrangers, des laboratoires publics ou privés.

\section{(c)(1)}

Distributed under a Creative Commons Attribution| 4.0 International License 


\title{
Time-function reliability of harbour infrastructures from stochastic modelling of corrosion
}

\author{
J. Boéro ${ }^{a}$, F. Schoefs ${ }^{b}$, H. Yañez-Godoy ${ }^{a}$ and B. Capra ${ }^{a}$ \\ ${ }^{a}$ OXAND S.A., 49 avenue Franklin Roosevelt, F-77210 Avon, France; ${ }^{b}$ LUNAM University, \\ University of Nantes-Centrale Nantes, GeM UMR CNRS 6183/ IUML FR CNRS 3473, 2, rue de \\ la Houssinière BP 9220844322 Nantes Cedex 3, France, and Institute in Civil and Mechanical \\ Engineering (GeM), UMR 6183, Nantes University, CNRS, PRES UNAM, 2 rue de la \\ Houssinière, F-44322 Nantes cedex 3, France
}

\begin{abstract}
This article summarises research led during the second phase of the French GEROM (risk management of maritime and river harbour structures) project in order to quantify the risks associated with vulnerable structures. A reliability analysis is applied here to steel sheet-pile seawalls. For this purpose, a stochastic (spatial-temporal) model of steel corrosion is proposed, based on a statistical analysis of data collected from wharves located in several French ports and of various ages. The predictions obtained from the corrosion model are then integrated into a reliability analysis to carry out a time-function reliability analysis of corroded harbour structures. The results are then compared and analysed both in terms of reliability and sensitivity to basic random variables. This approach allows suggesting preliminary requirements about maintenance optimisation.
\end{abstract}

Keywords: stochastic modelling; ageing law; corrosion; reliability; structural behaviour; steel sheet piles; harbour structures

\section{Introduction}

This article summarises research carried out in the framework of the French GEROM (risk management of marine and river harbour structures) project within the Scientific Interest Group MRGenCi (www.mrgenci.org). The main objective of the project is to assist owners in establishing decision-making procedures through maintenance master plans. The project is split into two phases: the initial phase consists of a study of maintenance management practices for harbour infrastructure and a preliminary risk analysis to identify vulnerable structures (ageing and issues); the second phase consists in quantifying the risks associated with the vulnerable structures identified in the initial phase.

The initial phase has been described in several papers (Boéro, Schoefs, Capra, \& Rouxel, 2009a \& 2009b). The present article deals only with the second phase, specifically the reliability analysis of steel sheet-pile seawalls undergoing uniform corrosion.

For this purpose, a stochastic (spatial-temporal) model of steel corrosion is proposed, based on a statistical analysis of data collected at various dates from several French ports in multiple zones that have been exposed to marine environment for varying lengths of time. At the preliminary stage, an in-depth understanding of the following issues is necessary: 
- Interpretation of the experimental data and physico-chemical phenomena which allows spatial corrosion to be treated essentially as a one-dimensional problem, according to the depth of the structures being considered (Boéro, Schoefs, Melchers, \& Capra, 2009c). An analysis of corrosion mechanisms shows that the process can be modelled by five independent random variables corresponding to five different exposure zones, each one based on a different random context.

- Probabilistic modelling for taking into account the variability of the phenomena. Having taken the preceding points into consideration, the stochastic time-dependent corrosion model presented in this paper is based on the temporal evolution of parameters for a given probability density function (here Gamma pdf) of the random variable "steel loss of thickness" in each exposure zone.

The paper focuses mainly on predictions resulting from the corrosion model that are used to perform a time-function reliability analysis of corroded harbour structures. A coupled approach between a FORM-algorithm and deterministic finite element model (Cast3M) is used to assess the reliability $\beta$ index. A complete probabilistic model is then suggested for accounting for uncertainties: a set of 10 random variables and processes is provided and justified both in terms of pdf (type and parameters) and correlations. The sensitivity analysis allows analysing the role of each exposure zone and of random variables with time. The paper concludes with preliminary requirements for maintenance purposes.

\section{Modelling of stochastic uniform corrosion fields in steel harbour structures based on feedback from French ports}

The proposed corrosion model takes into account the spatio-temporal aspects of uniform corrosion on steel sheet piles seawalls or cofferdams. Localised corrosion is not considered here. It is based, after data cleansing, on a statistical analysis of over 35,000 measurements taken from several French ports (Boéro et al., 2009c). This database is now extended to a European database called Euromarcor.

The model is based on the general hypothesis that corrosion can be considered to be a decoupled phenomenon on the $R^{2}$ plane of a structure; that is, along the length direction $x$ and along the depth $z$. The spatial aspect of corrosion in the $x$ direction is represented by the deterministic trend $T\left(x, Z_{E}, t\right)$ (see Equation (1)) which evolves in time $t$ and depends on the exposure zone $Z_{E}$ (tidal zone, immersion zone, etc.). The form of the deterministic tendency (linear, sinusoidal, etc.) is unique for each asset. It depends mainly on the environmental conditions to which the structure is exposed (marine currents, effluent discharge, etc.) (Boéro et al., 2009 c). Corrosion may be considered as being uniform in the $z$-direction within a given exposure zone $Z_{E}$ (tidal zone, immersion zone, etc.). It is a simplified assumption. For that reason, only the higher measure of corrosion (i.e. loss of thickness) in each zone $Z_{E}$ has been selected during the statistical treatment. The corrosion distribution $c\left(Z_{E}, t, \theta\right)$ is therefore assumed to follow the form in Equation (1), with a dependence with time $t$ and discretised along the depth $z$ by exposure zone $Z_{E}$. Thus the predictive corrosion model takes the following form (1):

$$
c\left(x, Z_{E}, t, \theta\right)=T\left(x, Z_{E}, t\right)+c\left(Z_{E}, t, \theta\right)
$$


where $c\left(x, Z_{E}, t, \theta\right)$ is the loss of thickness as a function of the $x$-coordinate and the time $t$, for the exposure zone $Z_{E}(\mathrm{~mm}), T\left(x, Z_{E}, t\right)$ is the deterministic trend with respect to a constant mean corrosion level throughout the $x$-direction and $c\left(Z_{E}, t, \theta\right)$ is the random variable representing the loss of thickness with time $t$ for the exposure zone $Z_{E}$ $(\mathrm{mm})$. It is important to emphasise that the statistical parameters for the random variable $c\left(Z_{E}, t, \theta\right)$ may vary throughout the length $x$ of the structure, depending on the heterogeneity of the environment (concentrated discharges, etc.) (Schoefs, 2010). After identifying the heterogeneous zones, the random variable $c\left(Z_{E}, t, \theta\right)$ representing the thickness loss, can be discretised in the $x$-direction. From a first statistical analysis, it has been shown that the various environments along the French coasts (Atlantic, Mediterranean and Channel) do not affect the evolution of the long term corrosion (Boéro et al., 2009c). Thus the probabilistic model suggested by Melchers (1999) is not considered here.

The Gamma probability distribution function (pdf) is used to characterise the variability of the corrosion $c\left(Z_{E}, t, \theta\right)$, since it is the theoretical pdf that gives the best fit to empirical data according to the maximum likelihood estimate (Boéro, 2010). The Gamma pdf is characterised by a shape parameter $\alpha$ and a scale parameter $\beta$ which can be expressed as functions of the two first statistical moments (mean and standard deviation of steel loss of thickness) and which evolves, according to the present model and in the absence of other information on the stochastic structure, in a spatio-temporal manner. In fact, the auto-correlation with time and space is not available from the database and no publication suggests such a model until now: thus we have chosen here to drive the stochastic process of corrosion by indexing these pdf parameters in time and space. The mean and standard deviation of data taken in each exposure zone are then computed and a model with time is obtained by fitting this empirical evolution using the least-squares method and exponential functions. Figure 1 presents the fitting of the evolution of the mean and standard deviation of the loss of thickness with time and Figure 2 the Gamma pdf plotted for each zone at time $t=25$ years.

In agreement with literature, the average loss of thickness reaches a maximum value in the zone of low seawater level due to the differential aeration which is established between the tidal zone, very oxygenated, and the immersion zone (Memet, 2000). Moreover in the mud and immersion zones, this mean trend is shown to increase with time even after 30 years when stabilization is shown in the tidal zone. That reflects the well known effect of the anaerobic corrosion (Melchers \& Jeffrey, 2006). Note that this
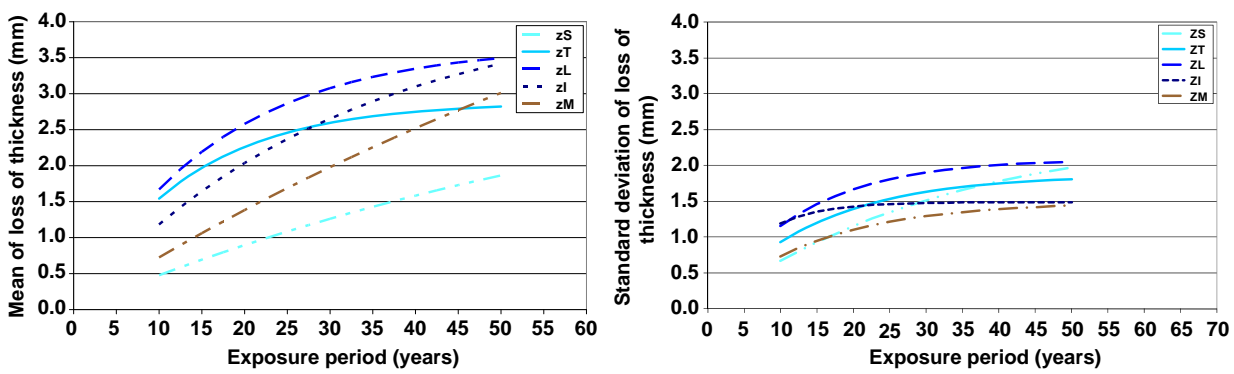

Figure 1. Evolution of the mean and the standard deviation of loss of thickness with time in each zone (exponential fitting). Legend: $Z_{S}=$ splash zone; $Z_{T}=$ tidal zone; $Z_{L}=$ low seawater level zone; $Z_{I}=$ immersion zone; $Z_{M}=$ mud zone. 


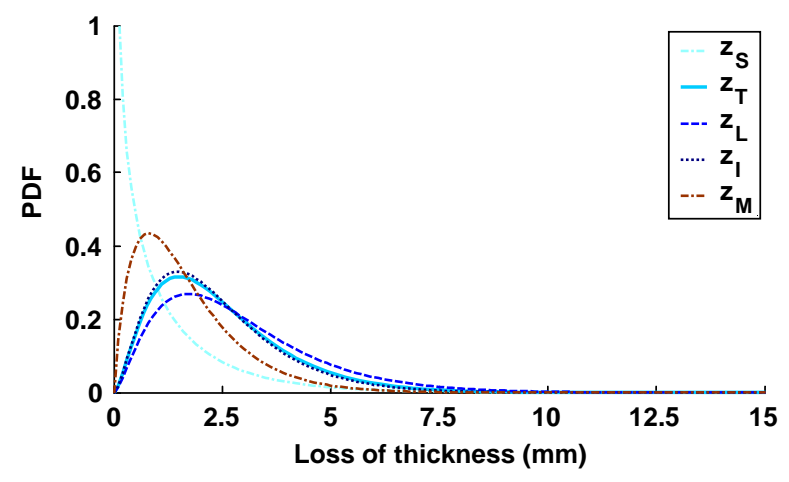

Figure 2. Pdf of the steel loss of thickness in each zone of exposure after a time period $t=25$ years.

is for the moment the single long-term model (adapted for corrosion after 30 years) fitted on on-site data available in the literature but that the corrosion during the first 8 years is not well modelled. Thus for a short term reliability analysis where the transition between the aerobic and anaerobic corrosion is needed, another model (Melchers \& Jeffrey, 2006, for instance) should be preferred.

This full-parametric modelling of spatio-temporal corrosion is very easy for reliability analysis, as well as in traditional engineering for the re-evaluation of corroded structures through the choice of probabilistic fractiles. Figure 3 presents the $95 \%$ fractiles of the loss of thickness at three exposure times: 10, 25 and 50 years. It illustrates that in some areas the mean of uniform corrosion is larger than in others $\left(Z_{L}\right.$ for instance) and that the width of the distribution support, illustrated here through the $95 \%$ fractile, varies depending on the area too: the dispersion of thickness loss is larger in area $Z_{L}$ than

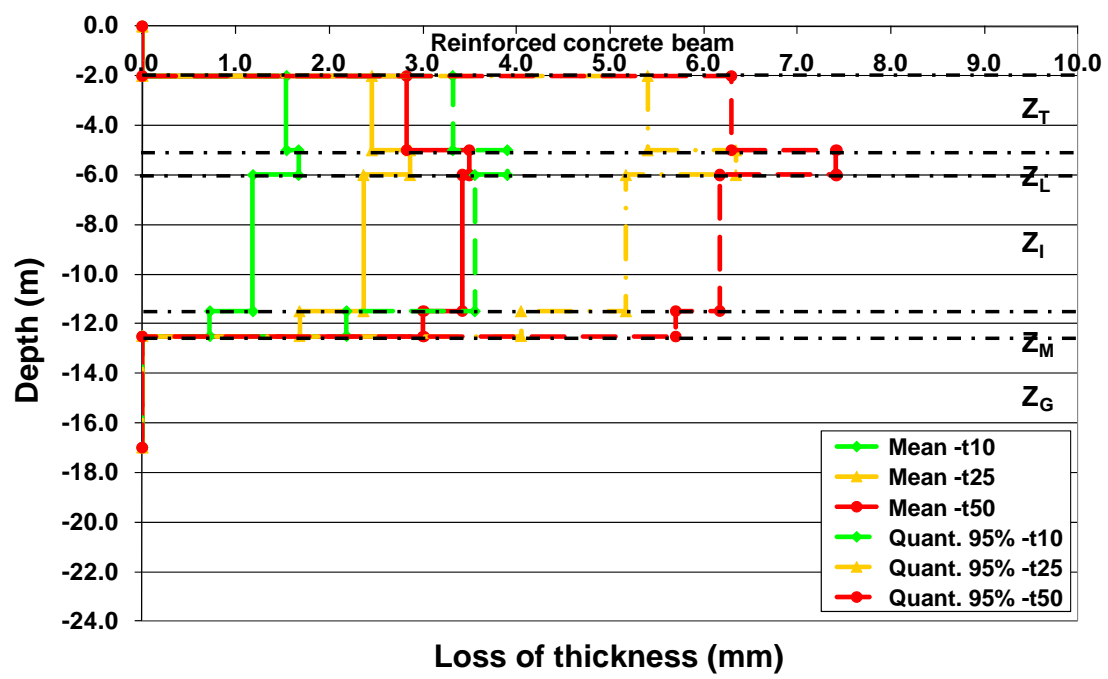

Figure 3. Mean value and $95 \%$ fractiles of steel thickness loss in each exposure zone at time 10,25 and 50 years. 


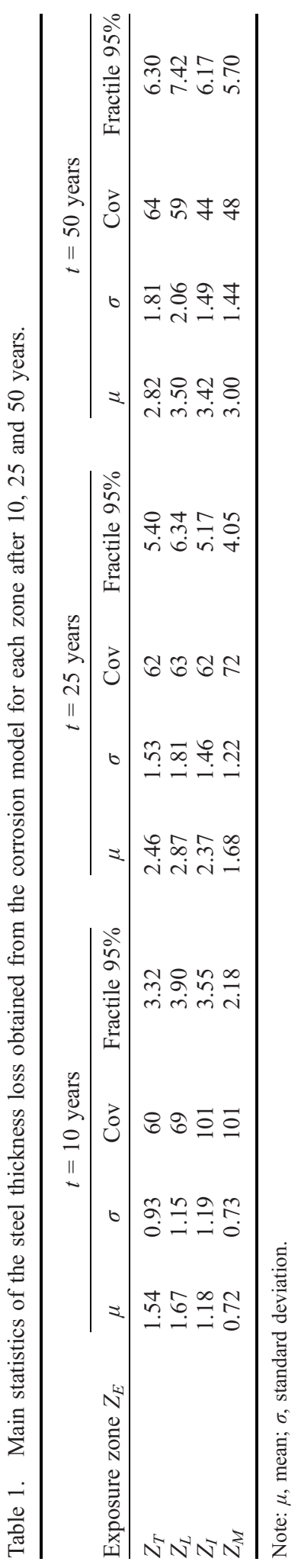


in others. This result is emphasized in Table 1 with the coefficient of variation $(\mathrm{CoV})$ which varies from 44 to $101 \%$ with depth and time.

\section{Simulation of the influence of corrosion on the mechanical behaviour of a steel sheet piles seawall}

\subsection{Description of the studied problem, assumptions}

The objective of this exploratory study is to integrate the previously defined spatiotemporal model of corrosion into a structural reliability analysis of a quay using the finite element method. The complete study presented here follows a first comprehensive study (Yáñez-Godoy, Boéro, Thillard, \& Schoefs, 2010). The example is representative of a current situation and considers a wharf with U-shaped piles, anchored with one level of passive tie rods (Figure 4). A synthesis of the main geometrical and mechanical characteristics of the quay is illustrated in Figure 4. This quay has been designed according to the French requirements ROSA2000 (CETMEF \& CSTB, 2000), without over-thickness to compensate future corrosion. Corrosion has been shown to be dependent on the location on the U pile: in-pans areas are less corroded than out-pans areas (Boéro et al., 2009c). With the view to simplify the analysis of results we consider in this paper that $U$ piles are uniformly corroded with the "out-pans" kinetics (see Figure 2 and Table 1). Moreover, if the corrosion has been shown to be stationary, the identification of the correlation length along $x$ is still a challenge (Boéro, 2010): we assume here that the correlation is negligible after 20 metres and that the wall can be modelled with a $2 \mathrm{D}$ model both in terms of mechanical behaviour and statistical properties (see Figure 4). Thus we consider the stability of a 2 metre wide sheet pile, that also corresponds to the distance between tie-rods. Finally, the tie-rods are protected (galvanisation) and are considered not to be affected by corrosion.

A load $q$ of $50 \mathrm{kPa}$ uniformly distributed on the surface is applied to the quay, and a tidal range of 5 metres is considered.

\subsection{Finite element model}

In terms of soil-fluid interaction, only the Archimedes buoyancy force on the soil is considered. The force of flow generated by viscous fluid friction on the soil grains is considered negligible, taking into account only the difference in elevation between the sea level and the water level in the embankment. The construction phases of the quay are not taken into account.
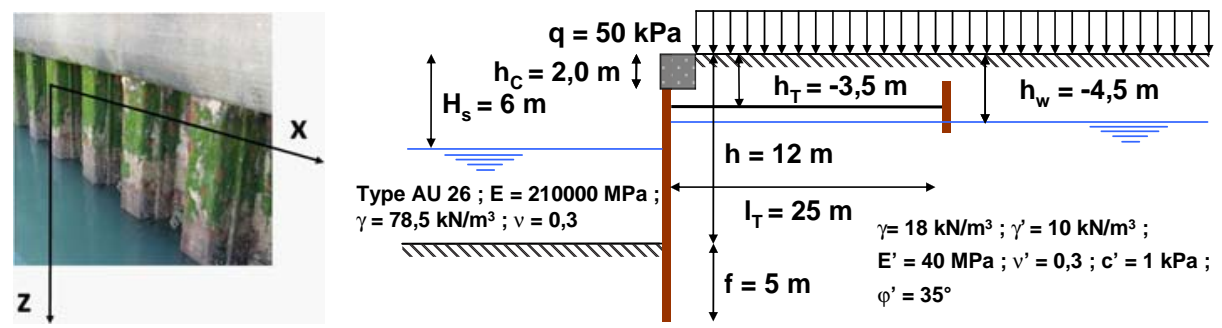

Figure 4. Main geometrical and mechanical characteristics of the quay. 
The soil is modelled as a homogeneous powder material that behaves in a perfectly elasto-plastic manner (Mohr-Coulomb criterion). The steel (present in the main wall, the pile anchorage and the tie-rods) is assumed to behave in an isotropic and linearly elastic manner. The elements of interface between the sheet-pile and the soil, laid out around the main wall, are described by the Coulomb friction criterion. The angle of the interface is equal to $2 / 3 \varphi^{\prime}$ (approximately 23.3 degrees) and the contact cohesion is negligible. The resistance of the tension elements is also zero, which allows for relative displacement between the nodes of the various interfaces. The finite element model has been developed within the CAST3M finite element computer code developed by the Atomic Energy Commission (CEA) (http://www.cast3m.cea.fr) and has been validated both with experimental data available in the literature (Von Wolffersdorff, 1994a, 1994b) and with a model obtained with Plaxis (PLAXIS, 2003). All the calibration tests are available in Boéro (2010).

\subsection{Impact of corrosion on the mechanical behaviour of the quay}

In the studied example, the steel sheet piles seawall is topped by a reinforced concrete beam 2 metres high (see Figure 4). Therefore, the steel sheet piles seawall is only in contact with the tidal zone, the zone of low seawater level, the immersion zone and the mud zone. The study was carried out for 4 different exposure times $(t=0,10,25$ and 50 years). As a first step, the influence of corrosion on the bending moment and the maximal normal stress (due to bending) were analysed, using the $95 \%$ fractile of steel loss of thickness, as predicted by the probabilistic model in each exposure zone along the depth of the seawall (see Figure 5).

Time-dependent corrosion causes a decrease in the geometric characteristics of the steel sheet piles seawall, thus making the wall more flexible. A decrease of the $95 \%$ fractile of the bending moment by around $20 \%$ of the initial state over 50 years is observed on the wall towards the seaside excavation. On the other hand, the normal stress increases in the same area. The bending moments in the zone of embedment and near the anchorage of the passive tie-rods are little affected by corrosion. Note that the zone where corrosion is most severe does not correspond with the most mechanically loaded zone.

These aspects are developed further in the following section, where predictions from the probabilistic corrosion model are used to carry out a time-dependent reliability analysis to evaluate the structural safety of corroded harbour structures.
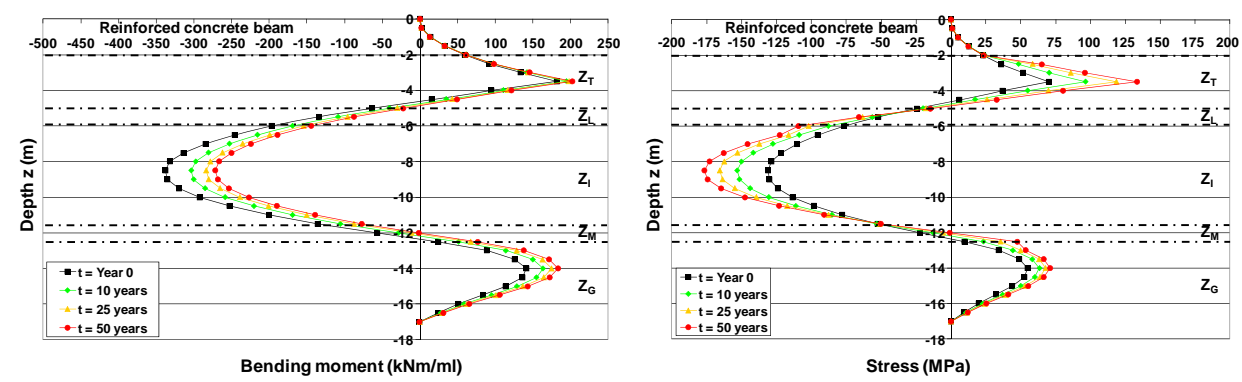

Figure 5. $95 \%$ fractiles of bending moment and stress with depth in the steel sheet-piles seawall. 


\section{Time-dependent structural reliability of a corroded steel sheet piles seawall}

\subsection{Definition of the limit-state criteria and methods for reliability assessment}

An evaluation of the probability of failure of old structures, sometimes designed with very different knowledge bases, is always a delicate problem. The formulation of the limit state is a crucial step: commonly, it is expressed for structural reliability in terms of displacement (service limit state) or stress (ultimate limit state). Figure 6 presents the evolution of the $95 \%$ fractile horizontal displacement with time $(0,10,25$ and 50 years) and depth: it is shown that where the displacement affects the service of the structure i.e. near the surface - (Schoefs, Clément, Boéro, \& Capra, 2010), the displacement is low in intensity and weakly affected by the corrosion.

Thus a reliability analysis based on the stress-based limit state is stated here (2):

$$
G(X(t))=\sigma_{e}-\sigma_{S}(t)
$$

where $X(t)$ is the vector of basic random variables $X_{i}$ or random processes $X_{i}(t), \sigma_{e}$ is the yield stress and $\sigma_{S}(t)$ the maximum stress in the steel sheet piles seawall at time $t$, along the depth $z$ (see Figure 5). It depends on the vector of basic random variables

$$
c=\left\{c_{Z_{T}}, c_{Z_{L}}, c_{Z_{I}}, c_{Z_{M}}\right\}
$$

where $c_{Z_{E}}=c\left(Z_{E}, t, \theta\right)$, where $\mathrm{ZE}$ is the exposure zone.

Other random variables are described in Table 2.

The probability of failure $P_{f}(t)$ according to Equation (2) can be assessed as a function of time by evaluating Equation (3):

$$
P_{f}(t)=P(G(X(t)) \leqslant 0)=P\left(\sigma_{S}(t) \geqslant \sigma_{e}\right)
$$

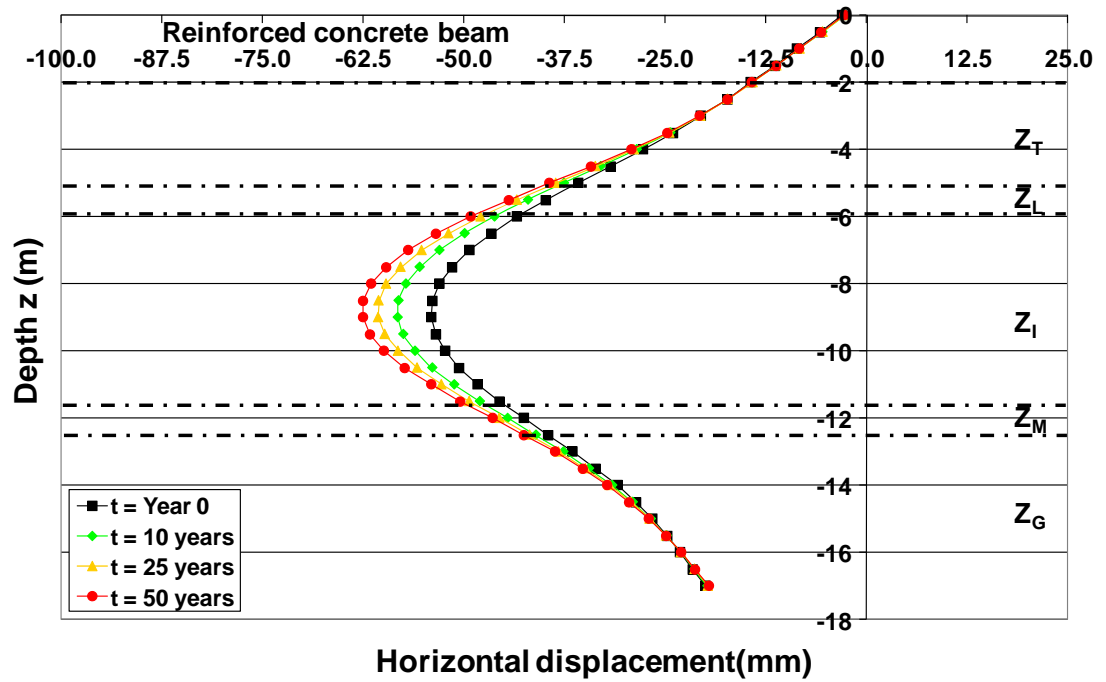

Figure 6. Horizontal displacement with depth along the steel sheet-piles seawall. 
Table 2. Selection of basic random variables for initial reliability assessment $(t=0)$.

\begin{tabular}{lcrcc}
\hline Random variable & Pdf & Mean & Standard deviation & $\begin{array}{c}\text { Coefficient of } \\
\text { variation }(\%)\end{array}$ \\
\hline Unit weight of dry soil $\gamma_{d}\left(\mathrm{kN} / \mathrm{m}^{3}\right)$ & Lognormal & 2006.4 & 160.50 & 8 \\
Unit weight of submerged soil $\gamma^{\prime}\left(\mathrm{kN} / \mathrm{m}^{3}\right)$ & Lognormal & 1003.2 & 80.30 & 8 \\
Angle of internal friction $\phi^{\prime}\left({ }^{\circ}\right)$ & Lognormal & 35.2 & 3.50 & 10 \\
Cohesion $c^{\prime}(\mathrm{kPa})$ & Lognormal & 1.5 & 0.75 & 50 \\
Loading service $q(\mathrm{kPa})$ & Lognormal & 51.5 & 10.30 & 20 \\
Elastic limit of steel $\sigma_{e}(\mathrm{MPa})$ & Lognormal & 266.3 & 13.30 & 5 \\
\hline
\end{tabular}

Quite a lot of numerical approaches, coupling a deterministic finite element model (here CAST3M) and a probabilistic model, can be selected for the evaluation of the probability of failure: Monte-Carlo simulations (Metropolis \& Ulam, 1949) and a non-intrusive spectral stochastic finite element method (SSFEM) (polynomial chaos expansion) (Ghanem \& Spanos, 2003; Puig, Poirion, \& Soize, 2002). We select here an algorithm that aims to compute the reliability index. This choice is governed by the fact that rules such as Eurocodes, ISO standards and specialized workgroups (Joint Committee on Structural Safety: JCSS, www.jcss.ethz.ch) provide target values for this quantity only. The relationship in Equation (4) allows linking probability of failure and reliability index.

$$
P_{f} \approx \Phi(-\beta)=1-\Phi(\beta)
$$

where $\Phi$ is the cumulative density function of the normalised standard normal pdf. The first order reliability method (FORM) is considered for the assessment of the reliability index. The algorithm GRACE (Nguyen, Duprat, Sellier, \& Pons, 2008) already available in the software CAST3M allows computing the FORM reliability index with an optimisation of computational time (limitation of the number of calls $N c$ to the deterministic finite element model). For our structure, a service life-time of 50 years is stated and, when considering the ultimate limit state (3), Eurocodes suggest a target value $\beta_{t}$ $=3.8$ (Calgaro, 1996). With the view to perform the reliability analysis, the normalised sensitivity factors $\alpha_{i}^{*}$ are computed, according to Equation (5):

$$
\frac{\partial \beta}{\partial u_{i}}=\frac{\partial}{\partial u_{i}}\left(\sum_{j=1}^{n} u_{j}^{2}\right)_{\vec{u}^{*}}^{1 / 2}=\alpha_{i}^{*}
$$

where $u_{i}$ stands for the co-ordinates on the axis of the variable $X_{i}$ of the so-called "design point" $P^{*}$ (Rackwitz \& Fiessler, 1978), in the standard space: the point with the highest likelihood of failure on the limit state surface. Note that these sensitivity factors are normalised (6):

$$
\sum_{i=1}^{n} \alpha_{i}^{* 2}=1
$$

\subsection{Selection of basic random variables}

Just after the building (no corrosion), only the six random variables presented in Table 2 have to be considered for the initial reliability assessment. The selected probability den- 
sity functions (pdf) and the corresponding parameters for the random variables involved in the study-case are given in Table 2. Due to the objectives of the study and with the view to analyse the effect of corrosion process only, other variables such as $H s$ (due to dredging) or $f$ (due to working step) are modelled as deterministic parameters.

After a few years, the four random processes describing the corrosion process have to be added. At each time step, the system is then influenced by a total of 10 random variables. We focus here on the times 10, 25, 50 years (see Table 1).

Note that properties of powder soil (angle of internal friction $\varphi^{\prime}$ and cohesion $c^{\prime}$ ) are correlated with a negative correlation (Breysse, 2010). It can be explained by two factors:

(1) From a statistical point of view first, uncertainties when performing the tests, plotting the Mohr circles and assessing the straight line that wraps these circles, link the two variables with a negative correlation: when reducing the distance between experimental data and the straight line, increasing $\phi^{\prime}$ leads to decreasing $c^{\prime}$.

(2) Second, a geotechnical reason can be argued: when the proportion of fines in the soil increases, $c^{\prime}$ increases to but $\phi^{\prime}$ decreases.

Quite a lot of values are suggested by authors. Here we choose a linear correlation equal to -0.75 .

\subsection{Results and analysis}

The evolution of the reliability index with time $\beta$ is calculated for the studied three exposure periods ( $t=10,25$ and 50 years) and plotted in Figure 7. The time-function structural reliability is an instantaneous reliability, an approach that is considered suffi-

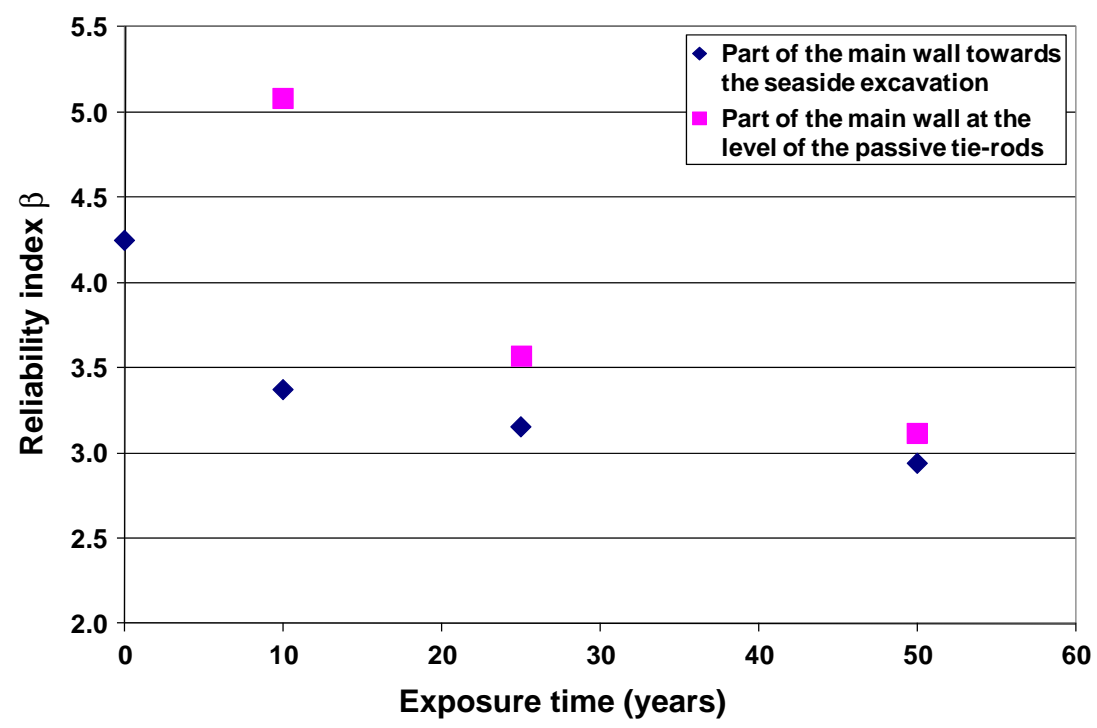

Figure 7. Evolution of the reliability index with time. 


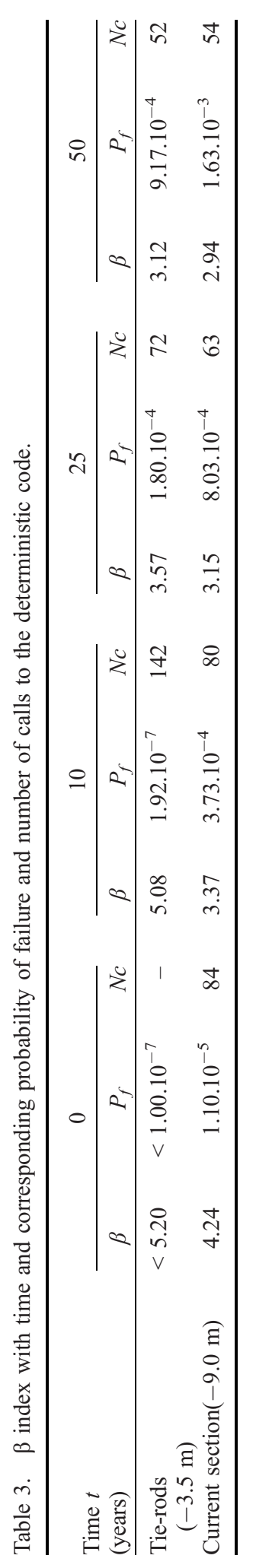




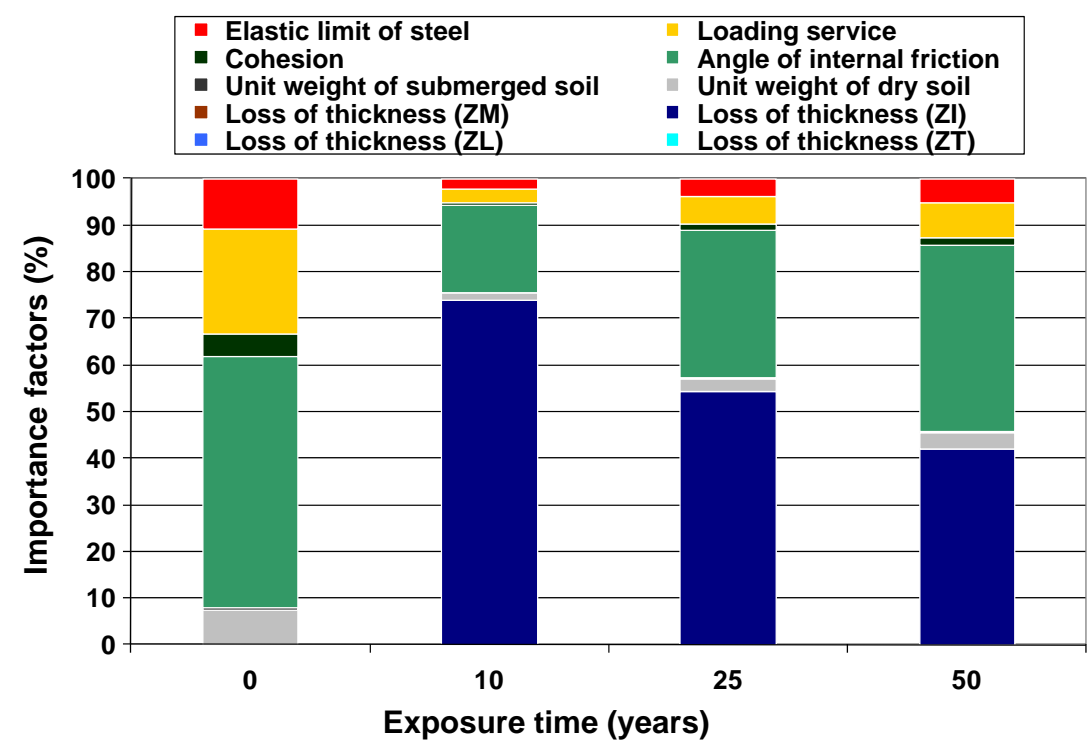

Figure 8. Evolution of importance factors with time (point of the section towards the seaside excavation).

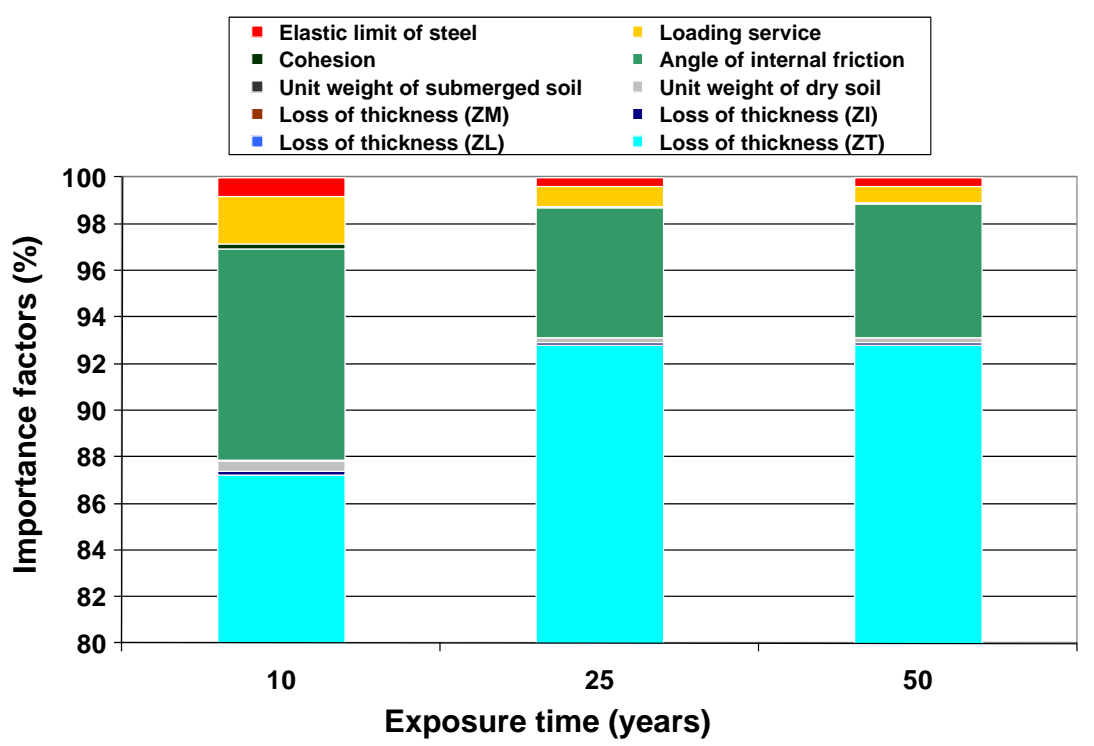

Figure 9. Evolution of importance factors with time (tie-rod zone).

cient insofar as the limit-state function $G$ is strictly decreasing and where only the random variables are time-indexed: no process is therefore considered.

The initial reliability index value is 4.24 but it falls quickly after almost 5 years under the target value of 3.8. The evolution is smoother after 10 years (as the corrosion is quite stabilised in the immersion area) and the reliability index decreases only from 3.4 to 3 from 10 to 50 years. Note for comparison that if we consider the cross-section 
near the tie-rod, the reliability index falls more quickly from 5.2 at $t=10$ to 3.1 after 50 years and can govern the reliability of such structures in some cases (see Figure 7). These reliability indices and the number of calls $N c$ to the deterministic code are reported in Table 3. Note that $N c$ decreases when $\beta$ decreases and is still less than 150 for probability of failures higher than $10^{-7}$.

Let us now focus on sensitivity factors. Figure 8 reports the values of these factors obtained when computing the reliability index at times $t=0,10,25$ and 50 years. The results are very interesting: at the beginning of the lifetime, the dominant random variables are angle of internal friction, service loading and steel yield stress with a pro-eminent role of the first $(55 \%)$. After 10 years, the role of the corrosion in zone $Z_{I}$ is already prominent (more than 70\%) and angle of internal friction follows. This role of corrosion decreases with time and is the same than the role of angle of internal friction after 50 years (almost 40\%). Note that of course this trend depends on the position of the steel section under consideration. If we focus on the section near the tie-rod (see Figure 9), the role of the corrosion random variable, here in area $Z_{T}$, increases with time.

These results show that space-variant reliability analysis is structural dependant. The critical section can change and in that case, the dominant random variable can change too. From the results illustrated on Figure 8 we deduce that the corrosion in the immersion zone in the first 25 years plays a dominant role except in the first years after building and that angle of internal friction is the second variable playing a significant role. From probabilistic modelling point of view, we suggest for such structures to refine the assessment of the distribution of the random variables (collection and treatment of data for distribution updating) in view to better represent the uncertainties and better estimate the reliability index: it is of first importance for the planning of maintenance to have a good precision on the modelling of corrosion in immersion area. After 25 years, the role of corrosion in immersion area decreases and the amount of collected data can be less. On the other hand, Figure 9 shows that corrosion in the tidal zone is more and more influent if we assess the reliability of the section near the tie-rod.

\section{Conclusion}

This article has presented a global vision of research carried out in the framework of the GEROM project. The first phase of this project produced an overview of actual current maintenance practices for the French ports, brought to light the non-uniformity of the asset base and the significance of the associated maintenance constraints. It is essential to integrate these aspects into a risk management, or any other methodology, in order to ensure its robustness.

The second phase was focused on the vulnerable harbour structures identified in the first phase and is the subject of the paper. Stochastic corrosion fields were modelled based on feedback from French ports. The resulting predictions were then integrated into a finite element model in order to carry out a sensitivity analysis of the mechanical behaviour of a quay undergoing corrosion.

Due to the large spatio-temporal variability of corrosion, and its influence on the stress-state and resistance of the structure, a mechanical reliability study was carried out using a FORM algorithm that couples a deterministic finite element model of the quay and a probabilistic model of random variables. The results of this analysis allowed identifying the most critical zone according to the depth of the quay, and for a given limitstate criterion. 
Finally, a study on the integration of other basic random variables, such as geotechnical soil characteristics, loads and environmental actions, is suggested. That allows estimating the reliability index with time and underlines the role of random variables with time. It is shown that the role of corrosion depends on the section under investigation and that this role, in terms of effect on reliability analysis, can decrease with time. These remarks are of first importance when planning inspection and maintenance strategies.

\section{Acknowledgements}

The GEROM project was carried out in French scientific group of interest on risk in civil engineering GIS MRGenCI (contact: Franck.Schoefs@univ-nantes.fr) and financed by Oxand. The authors would like to thank the CEA for their permission to use the Cast3M software.

\section{References}

Boéro, J., Schoefs, F., Capra, B., \& Rouxel, N. (2009a). Technical management of French harbour structures. Part 1: Description of built assets. PARALIA, 2, 6.1-6.11 (published, online 21 December 2009).

Boéro, J., Schoefs, F., Capra, B., \& Rouxel, N. (2009b). Technical management of French harbour structures. Part 2: Current practices, needs - Experience feedback of owners. PARALIA, 2, 6.13-6.24 (published, online 21 December 2009).

Boéro, J., Schoefs, F., Melchers, R., \& Capra, B. (2009c). Statistical analysis of corrosion process along French coast. ICOSSAR'09. Paper no. 528. Mini-symposia MS15. System identification and structural health monitoring, 13-19 September 2009, Osaka, Japan.

Boéro, J. (2010). Port infrastructure reliability: innovative approach of analysis and probabilistic modeling of inspection data - Application to the corrosion of metallic structures (in French) (Phd thesis). 26 October 2010, University of Nantes.

Breysse, D. (2010). Sécurité des fondations superficielles: le poids de la variabilité du sol. Proceedings of Journées Fiabilité des Matériaux et des Structures, Gème Journée Nationales de Fiabilité, 24-26 March 2010, INSA Toulouse.

Calgaro, J.A. (1996). Introduction aux Eurocodes. In: Presses de l'école nationale des ponts et chaussées, $200 \mathrm{pp}$.

CETMEF (Centre d'Etudes Techniques Maritimes et Fluviales), CSTB (Centre Scientifique et Technique du Bâtiment. (2000). Recommandations pour le calcul aux états-limites des Ouvrages en Site Aquatique. Cédérom ROSA 2000. In: Presses de l'école nationale des ponts et chaussées.

Ghanem, R., \& Spanos, P. (2003). Stochastic Finite Elements: A Spectral Approach (Rev. edn.). New York: Dover.

Melchers, R.E., \& Jeffrey, R. (2006). Models for the anaerobic phases of marine immersion corrosion. Corrosion Science, 48(7), 1791-1811.

Melchers, R.E. (1999). Corrosion uncertainty modeling for steel structures. Journal of Constructional Steel Research, 52, 3-19.

Memet, J.B. (2000). La corrosion marine des structures métalliques portuaires: étude des mécanismes d'amorçage et de croissance des produits de corrosion ( $\mathrm{PhD}$ thesis). Université de $\mathrm{La}$ Rochelle, France, 164 pp.

Metropolis, N., \& Ulam, S. (1949). The Monte Carlo Method. Journal of the American Statistical Association, 44(247), September, 335-341.

Nguyen, X.S., Duprat, F., Sellier, A., \& Pons, G. (2008). Méthode du gradient projeté avec contrôle d'erreur. Revue Européenne de Mécanique Numérique, 17, 1039-1056.

PLAXIS. (2003). Reference Manual. Version 8.

Puig, B., Poirion, F., \& Soize, C. (2002). Non-gaussian simulation using hermite polynomial expansion: convergences. Probabilistic Engineering Mechanics, 17, 253-264.

Rackwitz, R., \& Fiessler, B. (1978). Structural reliability under combined random load sequences. Computers \& Structures, 9, 489-494.

Schoefs, F. (2010). Probabilistic modelling of corrosion process along French coats: a multi-scale modelling from inspection data. Proceedings of 2nd International Conference on Applications Heritage and Constructions in Coastal and Marine Environment (MEDACHS'010). Session duratiNet technical session. Paper no. 55, 8 pp, 28-30 April 2010, La Rochelle (LEPTIAB), France. 
Schoefs, F., Clément, A., Boéro, J., \& Capra, B. (2010). "The $\alpha \delta$ method for modelling expert Judgment and combination of NDT tools in RBI context: application to Marine Structures", Structure and Infrastructure Engineering: Maintenance, Management, Life-Cycle Design and performance (NSIE). In J.R Casas \& A. O'Connor (Eds.) Special Issue "Monitoring, Modeling and Assessment of Structural Deterioration in Marine Environments", (6), 531-543, doi:10.1080/15732479.2010.505374.

Von Wolffersdorff, P.A. (1994a). Sheetpile wall verification test - Document for the prediction. Report of the University of Karlsruhe, $85 \mathrm{pp}$.

Von Wolffersdorff, P.A. (1994b). Results of the field test and evaluation of the predictions and subsequent calculations. Workshop Sheet Pile Test Karlsruhe, Delft University, Holland, 91 pp.

Yáñez-Godoy, H., Boéro, J., Thillard G., \& Schoefs F. (2010). Effect of corrosion on time-dependent reliability of steel sheet-pile seawalls in marine environment conditions. Paper no. 192. 6th International Conference on Concrete Under Severe Conditions. Environment and Loading, CONSEC'10, Session Performance in Severe Environment/Field Performance of Structures and Materials (9 pages). 7-9 June 2010, Mérida, Yucatán, México. 